\title{
Coercivity of Nd-Fe-B-type Fine Particles Prepared from Different Precursor Materials
}

\author{
K. M. Kim ${ }^{1}$, H. W. Kwon ${ }^{1 *}$, J. G. Lee ${ }^{2}$, and J. H. Yu ${ }^{2}$ \\ ${ }^{1}$ Pukyong National University, Busan 608-737, Korea \\ ${ }^{2}$ Korea Institute of Materials Science, Changwon 642-831, Korea
}

(Received 2 December 2014, Received in final form 11 March 2015, Accepted 12 March 2015)

\begin{abstract}
Fine Nd-Fe-B-type particles were prepared by ball milling of different types of Nd-Fe-B precursor materials, such as die-upset magnet, HDDR-treated material, and sintered magnets. Coercivity dependence on the grain and particle size of the powder was investigated. Coercivity of the milled particles was reduced as the particle size decreased, and the extent of coercivity loss was dependent upon the precursor material. Coercivity loss in the finely milled particles was attributed to the surface oxidation. The extent of coercivity loss in the fine particles was closely linked to grain size of the precursor materials. Coercivity loss was more profound for the fine particles with larger grain size. Contrary to the fine particles from the sintered magnets with larger grain size the fine particles $(\mathbf{1 0} \mathrm{um})$ from the die-upset magnet and HDDR-treated material with much finer grain size still retained high coercivity (>10 kOe for die-upset magnet, $>4 \mathrm{kOe}$ for HDDR-treated material).
\end{abstract}

Keywords : coercivity, Nd-Fe-B particle, surface oxidation, relative surface-grains-volume

\section{Introduction}

High performance Nd-Fe-B-type bonded micro-magnets have increasingly found new applications, such as the magnet in micro-motor and the like [1-3]. For preparation of the high performance bonded micro-magnet, fine $\mathrm{Nd}$ Fe-B-type anisotropic particles are required and they need to maintain the high permanent magnetic performance even when they are processed to fine particles. The easiest way to prepare the fine particles is probably a crushing and milling of bulk Nd-Fe-B-type precursor magnets with high performance, such as, die-upset magnet, sintered magnet. In addition to those materials, the HDDR-treated material may also be a promising candidate as a precursor material for fine particles. It is common, however, that the fine particles prepared by mechanical milling of the precursor materials lose significantly the coercivity [3-5]. This coercivity reduction due to the mechanical milling is considered to be linked closely to the structural damage, oxidation caused by the milling. Microstructure (in particular, grain size) of the precursor materials can also be an important factor controlling coercivity of the mechanically

CThe Korean Magnetics Society. All rights reserved.

*Corresponding author: Tel: +82-51-629-6362

Fax: +82-51-629-6353, e-mail: hwkwon@pknu.ac.kr milled fine particles. In this article, coercivity dependence on the grain and particle size of the powder prepared by mechanical milling of various Nd-Fe-B-type precursor materials was investigated.

\section{Experimental Work}

Four different types of $\mathrm{Nd}-\mathrm{Fe}-\mathrm{B}$ precursor materials were used in the present study, and they had uniquely different grain size as presented in Table 1. Also included in Table 1 is the material property parameters of the precursor materials. Fine Nd-Fe-B-type particles were prepared by ball milling (in cyclohexane, for 4-10 hr) of the precursor materials. Size of the milled particles was controlled by adjusting the milling time. Microstructure of the materials was observed by SEM and TEM. Oxygen content in the materials was determined by Oxygen Analyzer (LECO TC400). Content of residual hydrogen in the HDDR-treated material was analysed by Hydrogen Determinator (LECO RH-600). Crystallographic examination of the materials was performed by X-ray diffraction (XRD) $\left(\mathrm{Cu}-\mathrm{K}_{\alpha}\right.$ radiation). Magnetic characterization of the particles was performed by VSM after magnetizing using a pulsing field (4.5 T). 
Table 1. Material property details of precursor materials.

\begin{tabular}{ccccc}
\hline \hline & die-upset & HDDR-treated & sintered $\mathrm{A}$ & sintered B \\
\hline chemical-composition & $\mathrm{Nd}_{13.6} \mathrm{Fe}_{73.6} \mathrm{~B}_{5.6} \mathrm{Co}_{6.6} \mathrm{Ga}_{0.6}$ & $\mathrm{Nd}_{12.5} \mathrm{Fe}_{80.6} \mathrm{~B}_{6.4} \mathrm{Ga}_{0.3} \mathrm{Nd}_{0.2}$ & $\mathrm{Nd}_{12} \mathrm{Dy}_{1} \mathrm{Fe}_{80.85} \mathrm{~B}_{6} \mathrm{Zr}_{0.15}$ & $\mathrm{Nd}_{10} \mathrm{Pr}_{2.5} \mathrm{Fe}_{80.4} \mathrm{~B}_{6} \mathrm{Cu}_{0.1} \mathrm{Ga}_{1}$ \\
$\mathrm{iH} \mathrm{c}_{\mathrm{c}}(\mathrm{kOe})$ & 17.8 & 13.5 & 15.5 & 12.5 \\
$\mathrm{Br}(\mathrm{kG})$ & 12.5 & 12.9 & 14.3 & 13 \\
$(\mathrm{BH})_{\max }(\mathrm{MGOe})$ & 35 & 37 & 48 & 35 \\
mean grain size $(\mathrm{um})$ & $\mathrm{d}=0.15, \mathrm{t}=0.05$ & 0.3 & 8 & 15 \\
remark & & $\mathrm{H}_{2}=1500 \mathrm{ppm}$ & & \\
\hline
\end{tabular}

\section{Results and Discussion}

Fig. 1 shows coercivity variation of the particles prepared from the different precursor materials as a function of particle size. Coercivity of the milled particles prepared from all the precursor materials was reduced as the particle size decreased, and the extent of coercivity loss was dependent upon the precursor material. The particles from die-upset magnet could maintain high coercivity $(>10 \mathrm{kOe})$ even when the material was milled down to fine particles $(\sim 10 \mu \mathrm{m})$. The particles from the sintered magnets $\mathrm{A}$ and $\mathrm{B}$ exhibited radical coercivity reduction with decreasing particle size, and the coercivity loss started even in the lightly milled particles. The particles from the HDDR-treated material showed a moderate coercivity loss with respect to the particles from other types of precursor materials. The particles $(\sim 10 \mu \mathrm{m})$ from the HDDR-treated material still maintained considerable coercivity over $4 \mathrm{kOe}$. On the other hand, the particles $(\sim 10 \mu \mathrm{m})$ from the sintered magnets $A$ and $B$ exhibited radical loss of coercivity. Retained coercivity in the fine particle $(\sim 10 \mu \mathrm{m})$ prepared from different precursor material was in the order of die-upset magnet $(10.2 \mathrm{kOe})$,

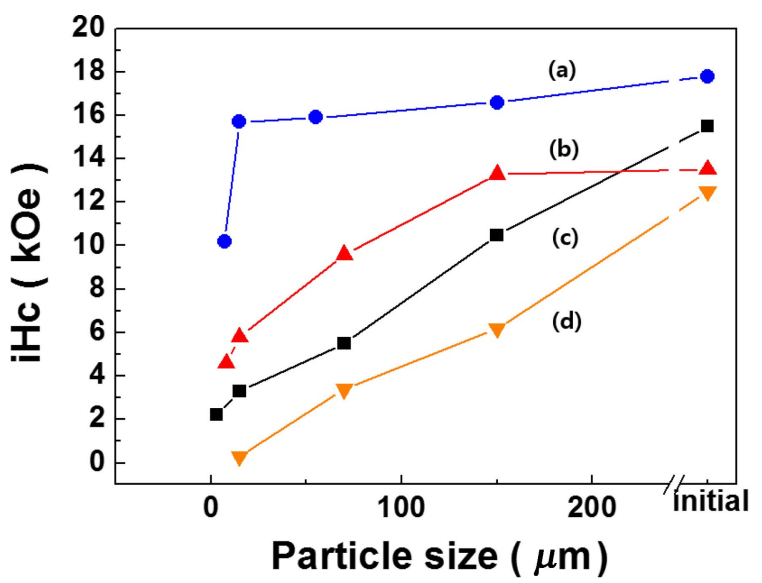

Fig. 1. (Color online) Coercivity variation of the particles prepared from the different precursor materials as a function of particle size. (a) die-upset magnet, (b) HDDR-treated material, (c) sintered magnet A, (d) sintered magnet B.
HDDR-treated material (4.1 kOe), sintered magnet A (2.2 $\mathrm{kOe})$, and sintered magnet $\mathrm{B}(0.3 \mathrm{kOe})$. It is interesting that this order is linked closely to the grain size of the precursor materials, and this is discussed afterwards.

The probable causes for the coercivity reduction due to mechanical milling would be the structural damage and/or surface oxidation. Introduction of structural damage in the milled particles was examined by diffraction peak broadening (FWHM) in XRD diffraction pattern of the heavily milled particles $(\sim 10 \mu \mathrm{m})$, which is the most common parameter indicating micro-strain in a crystalline material, and some of the major diffraction peaks of the $\mathrm{Nd}_{2} \mathrm{Fe}_{14} \mathrm{~B}$ type matrix phase were shown in Fig. 2. Also included are the results of the lightly milled precursor materials $(\sim 300 \mu \mathrm{m})$ for comparison. Although, unlike the case of soft magnet material, the micro-strain is not believed to influence markedly the coercivity in the very hard magnetic $\mathrm{Nd}-\mathrm{Fe}$-B-type material, it is interesting to see the presence of micro-strain in the heavily mechanical-milled materials in the present study. It appeared that the FWHM values were not different significantly before and after the heavy mechanical milling for all the precursor materials. This implies that little structural damage has been introduced in the milled particle and the coercivity reduction caused by mechanical milling may not be attributed to the structural damage. Interesting finding in the XRD results was that unlike the finely milled particles from the other types of precursor materials the finely milled particles from HDDR-treated material showed significant shift of diffraction peak position of the $\mathrm{Nd}_{2} \mathrm{Fe}_{14} \mathrm{~B}$-type matrix phase towards higher angle with respect to the material before milling. This indicates lattice shrinkage of the $\mathrm{Nd}_{2} \mathrm{Fe}_{14} \mathrm{~B}$-type phase due to milling, and lattice parameters changes are presented in Table 2. No noticeable change in lattice parameters was observed in the materials except for the HDDR-treated material. The lattice shrinkage of the $\mathrm{Nd}_{2} \mathrm{Fe}_{14} \mathrm{~B}$-type phase in the fine particles from the HDDR-treated material is attributed to desorption of some of the residual hydrogen in the HDDR-treated material [68]. It is of interest to find the fact that the residual hydrogen in the HDDR-treated Nd-Fe-B-type material can be 

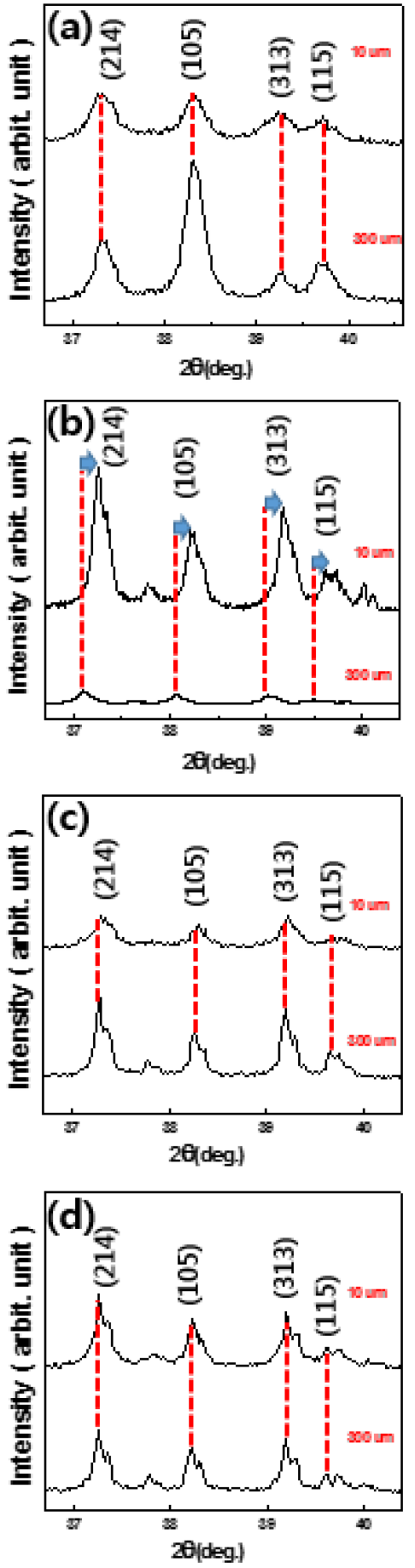

Fig. 2. (Color online) X-ray diffraction peak of the $\mathrm{Nd}_{2} \mathrm{Fe}_{14} \mathrm{~B}$ type matrix phase before and after heavy milling (10 um). (a) die-upset magnet, (b) HDDR-treated material, (c) sintered magnet $A$, (d) sintered magnet $B$.

desorbed significantly by mechanical milling. Thermal and mechanical energy provided by the mechanical milling is considered to cause the hydrogen desorption. Based upon the lattice parameter change due to hydrogen desorp-
Table 2. Lattice parameter change in the $\mathrm{Nd}_{2} \mathrm{Fe}_{14} \mathrm{~B}$-type matrix phase after heavy milling $(10 \mu \mathrm{m})\left(\mathrm{a}_{\mathrm{o}}, \mathrm{a}_{\mathrm{f}}\right.$ : lattice parameter before and after milling, respectively)

\begin{tabular}{cccccc}
\hline \hline $\begin{array}{c}\text { lattice } \\
\text { parameter }\end{array}$ & die-upset & $\begin{array}{c}\text { HDDR- } \\
\text { treated }\end{array}$ & $\begin{array}{c}\text { sintered } \\
\mathrm{A}\end{array}$ & $\begin{array}{c}\text { sintered } \\
\mathrm{B}\end{array}$ \\
\hline \multirow{4}{*}{$\mathrm{a}(\AA)$} & $\mathrm{a}_{0}$ & 8.792 & 8.842 & 8.802 & 8.792 \\
& $\mathrm{a}_{\mathrm{f}}$ & 8.800 & 8.815 & 8.803 & 8.792 \\
& $\Delta \mathrm{a}(\%)$ & 0.09 & -0.31 & 0.01 & 0 \\
\hline \multirow{4}{*}{$\mathrm{c}(\AA)$} & $\mathrm{c}_{0}$ & 12.190 & 12.251 & 12.179 & 12.190 \\
& $\mathrm{c}_{\mathrm{f}}$ & 12.190 & 12.225 & 12.196 & 12.190 \\
& $\Delta \mathrm{c}(\%)$ & 0 & -0.21 & 0.14 & 0 \\
\hline \multirow{4}{*}{$\mathrm{v}\left(\AA^{3}\right)$} & $\mathrm{v}_{0}$ & 942.278 & 957.795 & 943.571 & 942.278 \\
& $\mathrm{v}_{\mathrm{f}}$ & 943.993 & 949.934 & 945.102 & 942.278 \\
& $\Delta \mathrm{v}(\%)$ & 0.18 & -0.82 & 0.16 & 0 \\
\hline
\end{tabular}

tion, the estimated amount of hydrogen desorbed by the heavy ball milling $(\sim 10 \mu \mathrm{m})$ in the HDDR-treated Nd-FeB-type material is almost equivalent to that achieved by thermal degassing (heating up to $700^{\circ} \mathrm{C}$ under vacuum) of the material. The thermal degassing brought about significant reduction of residual hydrogen content in the HDDRtreated material from around $1500 \mathrm{ppm}$ to $1100 \mathrm{ppm}$ [9]. Obviously, the hydrogen desorption caused by mechanical milling is not linked to the coercivity reduction in the milled HDDR-treated material because the desorption of hydrogen from the $\mathrm{Nd}_{2} \mathrm{Fe}_{14} \mathrm{~B}$-type phase enhances slightly the anisotropy field $\left(H_{A}\right)[10,11]$ of the phase. Coercivity would, then, have to be enhanced, but this is not the case in the present work.

Most probable reason for the coercivity reduction due to milling may be attributed to the surface oxidation. Although the materials were milled in cyclohexane, the chance of surface oxidation of the milled particles during milling and handling in open air was inevitable. Oxygen content in the milled fine particles increased radically (Table 3), and this may be due to surface oxidation. Oxidation of the $\mathrm{Nd}_{2} \mathrm{Fe}_{14} \mathrm{~B}$-type matrix phase leads to the formation of magnetic soft phases $\alpha-\mathrm{Fe}, \mathrm{Fe}-\mathrm{B}$ compound at the surface of the fine particles [12-14], which leads to coercivity reduction. The impact of surface oxidation on the coercivity loss may be dependent upon the particle

Table 3. Oxygen content (ppm) in the materials before and after heavy milling $(10 \mu \mathrm{m})$.

\begin{tabular}{ccccc}
\hline \hline & die-upset & $\begin{array}{c}\text { HDDR- } \\
\text { treated }\end{array}$ & $\begin{array}{c}\text { sintered } \\
\mathrm{A}\end{array}$ & $\begin{array}{c}\text { sintered } \\
\mathrm{B}\end{array}$ \\
\hline $\begin{array}{c}\text { initial } \\
\text { milled particle } \\
(10 \mu \mathrm{m})\end{array}$ & 1630 & 2830 & 2020 & 2080 \\
& 8620 & 14110 & 9620 & 9780 \\
\hline
\end{tabular}




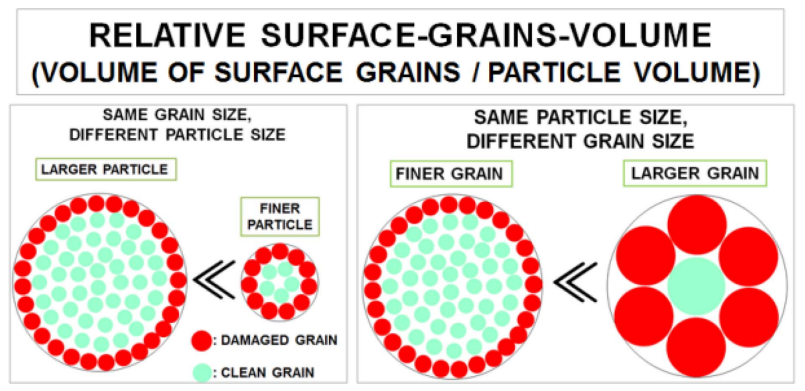

Fig. 3. (Color online) Schematic showing the comparison of relative surface-grain-volume for the particles with different particle and grain size.

size. The finer particle size becomes the greater the relative surface-grains-volume in the particles becomes (Fig. 3). Thus the impact of oxidized surface on the coercivity loss may become more profound for the finer particles. This can explain the dependence of coercivity of milled particles on the particle size. Because the major cause of coercivity reduction due to the mechanical milling is surface oxidation, prevention of further surface oxidation is required for practical use of the finely milled Nd-Fe-B-type particles, and this can be accomplished by surface coating technique using organic agents, such as epoxy, nylon resin.

The present findings also showed that the extent of coercivity loss in the finely milled particles $(\sim 10 \mu \mathrm{m})$ was dependent upon the precursor materials. The coercivity loss rate $\left(\mathrm{HLR}=\left(H_{o}-H_{m}\right) / H_{o} \times 100 \%, H_{o}=\right.$ initial coercivity, $H_{m}=$ coercivity of milled particles) in the finely milled particle $(\sim 10 \mu \mathrm{m})$ is in order; sintered magnet $B$ $(12.5 \mathrm{kOe} \rightarrow 0.2 \mathrm{kOe}, \mathrm{HLR}=98 \%)>$ sintered magnet $\mathrm{A}$

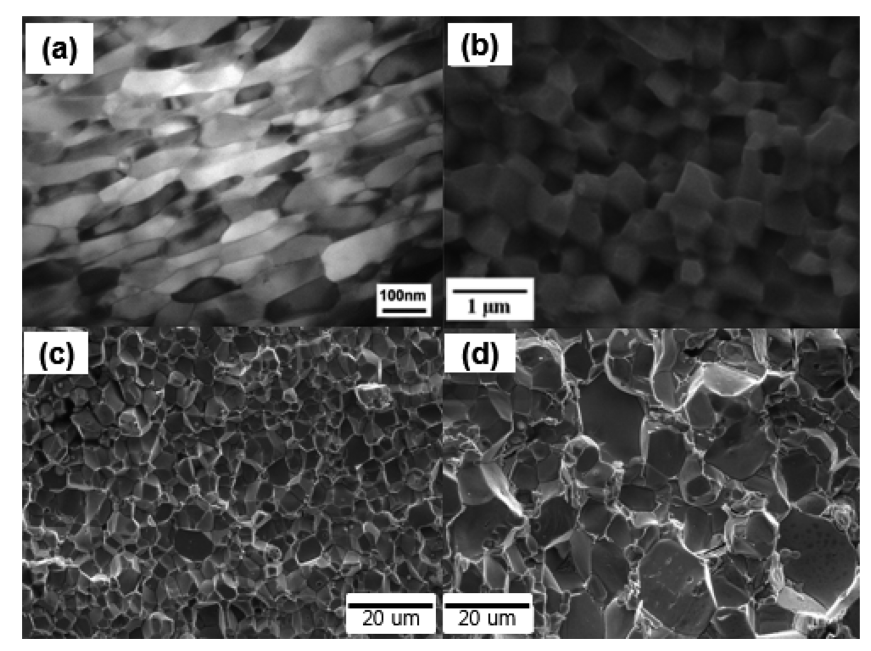

Fig. 4. Microstructure of the precursor materials showing uniquely different grain structure. (a) die-upset magnet, (b) HDDR-treated material, (c) sintered magnet A, (d) sintered magnet $\mathrm{B}$.
$(15.5 \mathrm{kOe} \rightarrow 2.2 \mathrm{kOe}, \mathrm{HLR}=87 \%)>$ HDDR-treated material $(13.2 \mathrm{kOe} \rightarrow 4.1 \mathrm{kOe}, \mathrm{HLR}=70 \%)>$ die-upset magnet $(17.5 \mathrm{kOe} \rightarrow 10.2 \mathrm{kOe}, \mathrm{HLR}=43 \%)$. The dependence of coercivity loss rate on the precursor material can be explained by the difference of microstructure, in particular the grain size, of the materials and the relative surface-grains-volume. The precursor materials had uniquely different grain size of the $\mathrm{Nd}_{2} \mathrm{Fe}_{14} \mathrm{~B}$-type matrix grains (Fig. 4, Table 1). As the fine particle with larger grain size has greater relative surface-grains-volume, the impact of oxidized surface on the coercivity loss may become more profound for the particles with larger grain size (see Fig. 3). Therefore, the fine particles prepared from the precursor material with larger grain size exhibits higher coercivity loss rate.

\section{Conclusion}

Coercivity of the milled particles prepared from the different type of precursor materials was reduced as the particle size decreased, and this was attributed to the surface oxidation. The extent of coercivity loss in the finely milled particles was dependent upon the precursor material, and this was closely linked to the grain size of the precursor materials. Coercivity loss was more profound for the fine particle with larger grain size because of its greater relative surface-grains-volume. Residual hydrogen in the HDDR-treated Nd-Fe-B-type material was desorbed significantly by mechanical milling.

\section{Acknowledgement}

The author H.W. Kwon would like to acknowledge that the present work was supported by Pukyong National University Research Promotion Program (2011).

\section{References}

[1] S. Yamashita, J. Yamasaki, M. Ikeda, and N. Iwabuchi, J. Appl. Phys. 70, 6627 (1991).

[2] M. Nakano, R. Katoh, H. Fukunaga, S. Tutumi, and F. Yamashita, IEEE Trans. Magn. 39, 2863 (2003).

[3] Hajime Nakamura, Koichi Hirota, Masanobu Shimao, Takehisa Minowa, and Masakatsu Honshima, IEEE Trans. Magn. 41, 3844 (2005).

[4] A. S. Kim, G. H. Kim, S. Namkung, T. S. Jang, D. H. Lee, H. W. Kwon, and D. H. Hwang, IEEE Trans. Magn. 40, 2877 (2004).

[5] H. W. Kwon, I. C. Jeong, A. S. Kim, G. H. Kim, S. Namkung, T. S. Jang, and D. H. Lee, J. Magn. Magn. Mater. 304, e219 (2006).

[6] T. Nishiuchi, S. Hirosawa, M. Nakamura, M. Kakimoto, 
T. Kawabayashi, H. Araki, and Y. Shirai, IEEE Trans. on Electrical and Electronic Engineering 3, 390 (2008).

[7] Md. A. Matin, H. W. Kwon, J. G. Lee, J. H. Yu, T. H. Kim, and C. W. Yang, IEEE Trans. Magn. 49, 3398 (2013).

[8] H. W. Kwon, J. G. Lee, and J. H. Yu, J. Appl. Phys. 115, 17A727-1 (1991).

[9] Md. A. Matin, H. W. Kwon, J. G. Lee, and J. H. Yu, IEEE Trans. Magn. 50, 2100504 (2014).

[10] W. E. Wallace, F. Pourarian, A. T. Pedziwiatr, and E. B.
Botich, J. Less-Common Metals 130, 33 (1987).

[11] L. Y. Zhang, F. Pourarian, and W. E. Wallace, J. Magn. Magn. Mater. 71, 203 (1988).

[12] D. S. Edgly, J. M. Breton, J. M. Lemarchand, I. R. Harris, and J. Teillet, J. Magn. Magn. Mater. 128, L1 (1993).

[13] Y. Li, H. E. Evans, I. R. Harris, and I. P. Jones, Oxidation of Metals 59, 167, (2003).

[14] H. W. Kwon and J. H. Yu, J. Korean Magn. Soc. 22, 85 (2012). 